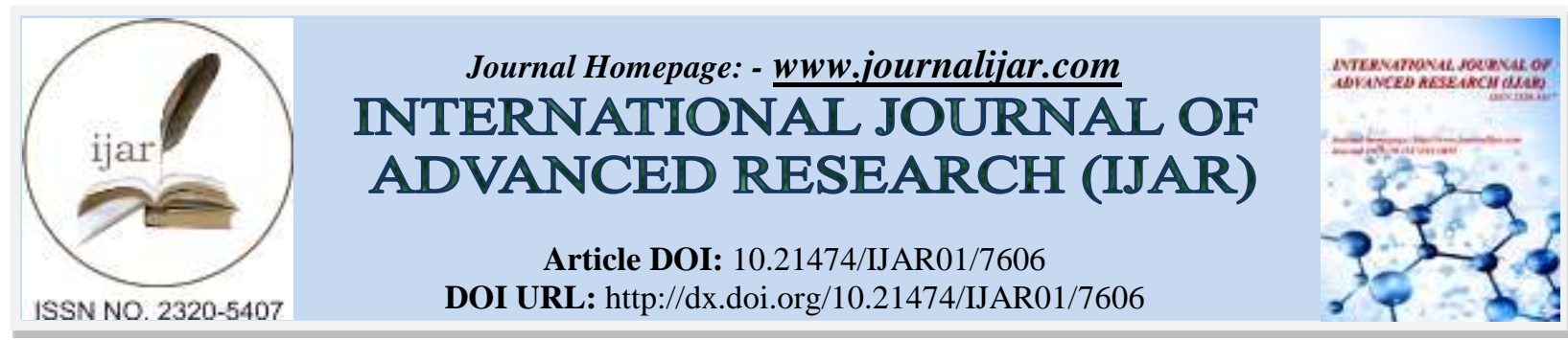

RESEARCH ARTICLE

\title{
ASSOCIATION BETWEEN PLASMA VITAMIN D LEVEL AND METASTASIS IN BREAST CANCER.
}

\section{Ira Astuti Hasibuan ${ }^{1}$, Sry Suryani Widjaja ${ }^{1}$ and Denny Rifsal Siregar ${ }^{2}$.}

1. Biomedical Departement of Medical Faculty of Universitas Sumatera Utara.

2. Oncology Departement of Adam Malik Hospital Medan.

\section{Manuscript Info}

Manuscript History

Received: 21 June 2018

Final Accepted: 23 July 2018

Published: August 2018

Keywords:-

Breast cancer, vitamin D, metastasis.

\section{Abstract}

Background: Metastasis is the leading cause of death in breast cancer. Experimental study found anti-invasive and anti-metastatic effects of vitamin $\mathrm{D}$ in cancer cells, but epidemiological studies supporting the anti-invasive and anti-metastatic effects of vitamin D are still inconsistent. The aim of the study was to investigate the association of plasma vitamin D levels and metastasis in breast cancer patients. Methods: A descriptive observational cross sectional study was performed on 50 newly diagnosed breast cancer patients at Adam Malik Hospital Medan. Plasma vitamin D levels were measured using enzyme-linked immunosorbent assay method. Chest $\mathrm{x}$-ray, liver ultrasonography and fine-needle biopsy were performed to find cancer cell rmetastasis. The relationship between plasma vitamin D levels and metastases was analyzed by unpaired t-test. RESULTS: The mean plasma vitamin D levels in patients with positive distant metastatis and in patients with negative distant metastases were $26.900 \pm 10.165$ $\mathrm{ng} / \mathrm{ml}$ and $27.561 \pm 8.467 \mathrm{ng} / \mathrm{ml}$. There were no association between plasma level vitamin $\mathrm{D}$ and metastasis in this study.

Copy Right, IJAR, 2018,. All rights reserved.

\section{Introduction:-}

Breast cancer is the most common malignancy experienced by women around the world. Currently breast cancer treatment has developed rapidly, but the process of cancer cell metastasis causes breast cancer morbidity and mortality is still high (Donepudi et al., 2014). Metastasis is the spread of cancer cells from the primary tumor to the surrounding tissues and other organs that are far away. The process of cancer cell spreading from primary tumor to formation of new tumor colony that is located far from primary tumor through several stages is known as invasion metastasis cascade. The tumor cells first damage the extracellular matrix component, enter the blood circulation and have the ability to survive in the blood circulation, penetrate the blood vessel wall to the remote tissue parenchyma, then proliferate until it reach a palpable size as a metastatic lesion ( Lambert et al., 2017).

Vitamin D has anti-cancer effects of anti-proliferation, pro-differentiation, pro apoptosis, anti angiogenesis, antiinvasion and anti-metastasis. Vitamin D acts as a steroid hormone that has a receptor in the cell nucleus and helps regulate the transcription of some genes involved in cell growth (Xi et al., 2017). Vitamin D is produced in the skin from 7-dehydrocholesterol material following sufficient sunlight ( ultraviolet B ) exposure.Vitamin D is also found in fortified milk, fatty fish, egg, cod liver oil and vitamin supplements . Vitamin D from all sources undergoes hydroxylation in the liver to become the circulating prohormone 25 -hydroxyvitamin $\mathrm{D}_{3}(25 \mathrm{OH}-\mathrm{D}$ ) by the $25 \alpha$ - 
hydroxylase ( CYP27A1 ). Later, the 1 $\alpha$-hydroxylase ( CYP27B1 ) enzyme converts 25(OH)D to 1,25dihydroxyvitamin $\mathrm{D}(1 \alpha, 25[\mathrm{OH}] \mathrm{D})$ mainly in the kidney. $1 \alpha, 25(\mathrm{OH}) \mathrm{D}$ is the most active form of vitamin $\mathrm{D}$ and is responsible for its biological actions. However,total body vitamin D stores are best measured by assessing circulating levels of $25(\mathrm{OH}) \mathrm{D}$. 1 $1 \alpha, 25$-dihydroxyvitamin $\mathrm{D}_{3}$ circulates, bound to plasma vitamin $\mathrm{D}$ binding protein ( DBP ), to various target tissue including epithelial cells of the breast gland to exert its endocrine actions, which are mediated by the vitamin D receptor ( VDR ). Vitamin D regulates gene transcription for the proliferation, differentiation and apoptosis of target organ cells (Wang et al., 2012; Wu et al., 2015).

Initial invasion and metastasis process of cancer cells is the process of cell changes from epithelial cells into mesenchymal cells which is known as epithelial-mesenchymal transition (EMT). This transition causes cancer cells to be more motile, invasive and have capability to degrade extracellular matrix components. Vitamin D plays an essential role in maintaining the cell-cell adhesion system.. Vitamin D inhibits the epithelial-mesenchyme transition process by increasing e-cadherin expression, decreasing the expression of Snail, Slug and Twist, a transcription factor that plays a role in the epithelial-mesenchymal transition process (Chang et al., 2014). Vitamin D also reduces the ability of migrating cells to invade and develop secondary tumour by decreasing the activity of metalloprotease matrix (MMP), decreasing activity of plasminogen activator, increasing expression of plasminogen inhibitor 1 (PAI1) and increasing expression of MMP inhibitor (Krishnan et al., 2010). Contrary to the studies of anti-invasive and anti-metastatic effects of vitamin D, an invivo study found that long-term vitamin D supplementation triggered the progression of cancer and accelerated the occurrence of metastases into distant tissues (Ajibade et al., 2014 ; Anisiewicz et al., 2018). It seems that research on the anti-invasive and anti-metastatic effects of vitamin D is still inconsistent. The aim of this study was to determine whether plasma vitamin D levels are associated with metastatic status in breast cancer patients.

\section{Methods:-}

This cross-sectional observational study was approved by the ethical committee of Medical Faculty of Universitas Sumatera Utara. The study population was 50 newly diagnosed breast cancer patients who came to oncology clinic of Adam Malik Hospital Medan. After agreement to participate was obtained, in-person interviews were conducted to complete informed consent and to query participants on a number of potential risk factor including age at menarche, menopausal status and family history of breast cancer. A total of $5 \mathrm{ml}$ of venous blood was collected from each subject. Quantitative determination of 25(OH)D was done using 25-Hydroxy Vitamin D ELISA kit. Fine needle biopsy, liver ultrasonography and chest $\mathrm{x}$-ray were performed to asses metastasis of the tumour.

The collected data were loaded on statistical analysis softwae SPSS V..19. Values are presented as means \pm S.E.M. Statistical difference between two means was assessed using student's t test. The p values less than 0,05 were considered to be statistically significant.

\section{Results:-}

\section{Characteristics of subjects}

Table 1 summarizes the descriptive characteristics of the study population.. Subjects mean age at diagnosis was 53 years. The age range were $35-86$ years. The most age group is $40-49$ years as many as 21 people (42\%). Of 50 subjects, $20(40 \%)$ experienced menarche at age before 12 years. The majority of the subjects were postmenopausal (56\%). A family history of breast cancer was experienced by only 6 subjects (12\%) while 44 subjects $(88 \%)$ had no family history of breast cancer.

Table 1:- Characteristics of Subjects

\begin{tabular}{|lcc|}
\hline Subject charasteristicts & $\begin{array}{c}\text { Frequency } \\
(\mathrm{n})\end{array}$ & $\begin{array}{c}\text { Percentage } \\
(\%)\end{array}$ \\
\hline Age at diagnosis & 4 & 8 \\
$<40$ years & 21 & 42 \\
$40-49$ years & 16 & 32 \\
$50-59$ years & 9 & 18 \\
$>60$ years & 20 & 40 \\
Age at menarche & 19 & 38 \\
$\leq 12$ years & & \\
$13-14$ years & & \\
\hline
\end{tabular}




\begin{tabular}{|c|c|c|}
\hline \multirow{2}{*}{\multicolumn{3}{|c|}{$\begin{array}{l}>14 \text { years } \\
\text { Menopause status }\end{array}$}} \\
\hline & & \\
\hline Pre menopause & 22 & 44 \\
\hline Post menopause & 28 & 56 \\
\hline \multicolumn{3}{|c|}{ Family history of breast cancer } \\
\hline No & 44 & 88 \\
\hline Yes & 6 & 12 \\
\hline
\end{tabular}

\section{The association between vitamin $D$ plasma levels and metastatic status}

Mean plasma vitamin D levels of positive lymph node metastases group were $22.942 \pm 9.5257 \mathrm{ng} / \mathrm{ml}$ and mean plasma vitamin D levels in the positive lymph node metastasis group were $28.724 \pm 8.5369 \mathrm{ng} / \mathrm{ml}$. There were no significant difference of mean plasma vitamin $\mathrm{D}$ levels between two groups $(\mathrm{p}=0.052)$. The mean plasma vitamin D levels of the negative distant metastatic group were 27, $561 \pm 8,4627 \mathrm{ng} / \mathrm{ml}$ and mean plasma vitamin D levels in the positive distant metastasis group were $26,900 \pm 10,3165 \mathrm{ng} / \mathrm{ml}$. Statistically, there were no differences in means plasma vitamin $\mathrm{D}$ levels of the two groups $(\mathrm{p}=0.809)($ Table 2$)$

Table 2:- Association between plasma vitamin D levels with metastasis status of subject

\begin{tabular}{|lccc|}
\hline Metastasis & $\begin{array}{c}\text { frequency } \\
(\mathrm{n})\end{array}$ & $\begin{array}{c}\text { Plasma 25(OH)D level } \\
(\mathrm{ng} / \mathrm{ml}) \pm \mathrm{SD}\end{array}$ & $\mathrm{p}$ \\
\hline Lymph node metastasis & & & \\
No & 12 & $22,942 \pm 9,5257$ & 0,052 \\
Yes & 38 & $28,724 \pm 8,5369$ & \\
Distant metastasis & & & 0,809 \\
No & 33 & $27,561 \pm 8,4627$ & \\
Yes & 17 & $26,900 \pm 10,3165$ & \\
\hline
\end{tabular}

\section{Discussion:-}

This study assesed the association of plasma level vitamin D and metastasis status in breast cancer patients. Metastasis status were performed on lymph node metastasis and distant metastasis. Vitamin D levels were obtained before the subjects received chemotherapy treatment with the consideration that chemotherapy drugs affect vitamin D levels in the body. In this study most of breast cancer patients were in the age range 40-49 years. This result are consistent with a research in India which found as much as $69 \%$ of breast cancer patients are at age of 28-49 years (Sofi et al., 2018). Women and old age are the highest risk factors for breast cancer. These risk factors are associated with the effect of estrogen hormone exposure, ie early menarche, late menopause, oral contraceptives and therapeutic hormone consumption (Prabha et al., 2017). Bodicoat et al (2014) found a lower risk of breast cancer in menarche over the age of 15 years than at the age of 13-14 years. This is due to breast exposure to estrogen. If a woman had menarche at the age of 12 years, estrogen expression in her every menstrual cycle is higher than women who menarche at age above 12 years. The addition of menstrual period each year increases the breast cancer risk by $3 \%$ (Kaminska et al., 2015).

Family history of breast cancer in this study was experienced in 6 women (12\%). There was one patient that both her mother and sister suffered from breast cancer, while others had only one close family member suffered from breast cancer. Familial breast cancer has some characteristics including young age, high cancer grade with lymph node involvement and negative progesterone receptor status (Tazzite et al., 2013). A research found $5-10 \%$ of all hereditary breast cancers are caused by mutations of BRCA1, BRCA2 and Tp53. BRCA1 and BRCA 2 and Tp53 are tumor suppressor genes that maintain genome stability. Carrier of this gene mutation has high risk of breast cancer up to 80\% (Apostolou and Fostira 2013).

Lymph glands are a common site of cancer cells spreading through the lymphatic system. In this study higher mean plasma vitamin D levels were seen in the group with positive lymph node metastasis. There were differences in mean plasma vitamin D level in negative lymph nodes metastasis group and the positive lymph nodes metastasis group, but statistically the two group showed no significant association $(p=0.052)$. Wu et al $(2017)$ also found no difference in mean plasma vitamin $\mathrm{D}$ levels between patients with positive breast cancer lymph nodes metastasis and patients with negative lymph nodes metastasis. Different results were obtained in other study looking at the association of vitamin D with metastasis in the lymph nodes. Thanassithichai et al (2015) found vitamin D levels in 
breast cancer patients with positive lymph node metastases were significantly lower than vitamin D levels in breast cancer patients with negative lymph nodes metastasis $(p=0.006)$. Kim et al $(2011)$, who examined the association of vitamin D levels by molecular type, found a significant association between plasma vitamin D levels and lymph node metastases in non-luminal cancer types but not in the luminal type.

In this study, the mean plasma vitamin $\mathrm{D}$ levels between positive distant metastase group and negative distant metastase group did not differ significantly $(\mathrm{p}=0,809)$. This result contrast with study in Egypt. Elzehery et al (2016) found a significant association between hypovitaminosis D status and metastasis in breast cancer patients ( $p$ $=0.009$ ).

Adequate levels of vitamin D, vitamin D receptor and enzyme involved in vitamin D metabolism play a major role in producing anti-cancer vitamin $\mathrm{D}$ effects. In many tissues including breast tissue, the active form of vitamin $\mathrm{D}$ $1 \alpha, 25(\mathrm{OH})_{2} \mathrm{D}_{3}$ is produced and degraded locally due to the presence of CYP27B1 and CYP24A1 enzymes on the organ target. In cancer case, dysregulation of local vitamin D activity occurs in cancer cells. The number of vitamin $\mathrm{D}$ receptors decrease progressively in cancer cells (Jeon et al., 2018). In the invitro trial, as many as 60\% of experimental mice that had been conditioned to be suffered from breast cancer and loss of vitamin D receptors had metastases to the liver faster than control mice that did not lose vitamin D receptors (Williams et al., 2016). Dysregulation also occurs in mRNA of enzyme involved in the production and degradation of $1 \alpha, 25(\mathrm{OH})_{2} \mathrm{D}_{3}$. mRNA expression of CYP27B1 decreased and mRNA expression of CYP24A1 increased in breast cancer tissue compared to normal breast tissue (Zhalehjoo et al., 2017). Changes in the expression of mRNA in both enzymes cause decreasing of vitamin $\mathrm{D}$ active $1 \alpha, 25(\mathrm{OH})_{2} \mathrm{D}_{3}$ production while degradation of $1 \alpha, 25(\mathrm{OH})_{2} \mathrm{D}_{3}$ is increasing resulted in low vitamin $\mathrm{D}$ levels in breast cancer tissue.

The effects of vitamin D also differ on different molecular types of breast cancer. Vitamin D activity tends to be better in luminal types of breast cancer with positive estrogen receptor. Cells with positive estrogen receptors tend to have higher vitamin D receptor expression than cells with estrogen-negative receptors. This is proved by Kim et al (2011) who examined the relationship of vitamin D levels by molecular type. The study found a significant relationship between plasma vitamin D levels and lymph node metastases in non-luminal cancer (ER -), but not in the luminal type.

This present study suggests that vitamin D levels do not affect the incidence of lymph metastasis and distant metastasis. The anti-cancer effect of vitamin D occurs when all components of the vitamin D signal including vitamin D level, the enzymes involved in metabolism, vitamin D receptors and the target organ environments are well regulated. Vitamin D level measured in this study was vitamin D level in systemic circulation. In fact, there was dysregulation of vitamin D metabolism in breast cancer cell caused plasma level vitamin D might not exert anti metastatic effect in cancer cell. Furthermore, cancer is a complex disease, involving genetic and environmental factors. Genetic disorder is caused by various mutations and affect body's defense system. This condition is different among breast cancer patients, so the anti-cancer effect of vitamin D may be specific to certain types of breast cancer

\section{Conclusion:-}

There were no significant association between plasma vitamin D level and metastasis in this study. Further research are needed to look at the association of vitamin D levels with metastases based on histopathological grade and molecular type of breast cancer.

\section{References:-}

1. Ajibade AA, Kirk JS, Karasik E, Gillard B, Mosser MT, et al. Early Growth Inhibition is followed by increased metastatic disease with vitamin $D$ One 2014; 9(2)

2. Apoloslou P, Fostira F. Hereditary breast cancer : The era of new susceptibility genes. Biomed Research International 2013

3. Anisiewicz A, Pawlik A, Filip-Psurska, Turlej E, Dzimira S, Milczarek M et al. Unvaforable effect of calcitriol and its low-calcemic analogs on metastasis of 4T1 mouse mammary gland cancer. International Journal of Oncology 2018; 52:103 - 126

4. Bodicoat DH,Schoemaker MJ, Jones ME, McFadden E, Griffin J, Asworth A, J. Timing of pubertal stages and breast cancer risk: The breakthrough generations study. 2014. Breast Cancer Research; 16:R18 
5. Chang K, Chen S, Yeh C, Pang J, Shen S, Hsu J, et al. Mart-10, a less calcemik vitamin D analog, is more potent than 1 $\alpha, 25$-dihydroxyvitamin D3 inhibiting the metastatic potential of MCF-7 breast cancer cells in vitro. The Journal of Steroid Biochemistry and Molecular Biology 2014; 139: 54-60

6. Donepudi M, Kondapalli K, Apos J, Venkanteshan P. Breast cancer statistics and markers. Journal of cancer research and Therapeutics 2014; 10(3)

7. Elzehery RR, Baiomy AA, Hegazy MA, Fares R, El-Gilani A, Hegazi R. Vitamin D status, receptor gene Bsml(A/G) polymorphism and breast cancer in group of Egyptian females. The Egyptian Journal of Medical Human Genetics 2016,

8. Jeon S, Shin E. 2018. Exploring vitamin D metabolism and function in cancer. Experimental and Molecular Medicine; 50:20

9. Kim HJ, Lee YM, Ko BS, Lee JW, Yu JH, Son BH et al. Vitamin D deficiency is correlated with poor outcomes in patients with luminal-type breast cancer. Ann Surg Oncol 2011; $18: 1830-1836$

10. Krishnan AV, Swami S, Feldman D. Vitamin D and breast cancer : Inhibition of estrogen synthesis and signaling. Journal of Steroid and Molecular Biology 2010; 121: 343-348

11. Lambert AW, Pattabiraman DR, Weinberg RA. Emerging Biological Principles of Metastasis. Cell 2017; 168

12. Sofi NY, Jain M, Seenu V, Kamal VK, Pandey R. Nutritional risk factor and status of serum $25(\mathrm{OH}) \mathrm{D}$ levels in patient with breast cancer : a case control study in India. The Journal of Steroid and Biochemistry and Molecular Biologi 2018; 175: 55-59

13. Tazzite A, Jouhadi H, Saiss K, Benider A, Nadifi S, Relationship between family history of breast cancer and clinicopathological features in Moroccan patients. Ethiop J Health Sci. 2013; 23(2)

14. Thanasittichai S, Chaiwerawattana A, Prasitthipayong A. Association Of Vitamin D level with clinicopathological Features in breast cancer. Asian Pacific Journal of Cancer Prevention 2015; 16

15. Wang Y, Zhu J, DeLuca HF. Where is vitamin D receptor ? Archives of Biochemistry and Biophysics 2012; 532: 123-133

16. Yao S, Kwan ML, Ergas IJ, Roh JM, Cheng TD, Hong C. Higher serum level of vitamin D at diagnosis are associated with better survival in prospective cohort of 1666 women with breast cancer : A case-cohort analysis in pathways study. JAMA Oncol 2017; 3(3): 351-357

17. Williams JD, Aggarwal A, Swami S, Krishnan AV, Ji L, Albertelli MA, Feldman BJ. Tumor autonomous effects of vitamin D defisciency promote breast cancer metastasis. Endocrinology 2016;157(4): 1341-1347

18. Wu Y, Sarkissyan M, Clayton S, Chlebowski R, Vadgama J. Association of vitamin D3 level with breast cancer risk and prognosis in African-American and Hispanic Women. Cancers 2017;9:144

19. Wu X, Zhou T, Cao N, Ni J, Wang X. Role of vitamin D metabolism and activity on carcinogenesis. Oncology Research 2015; 22: 129-137

20. Zhalehjoo N, Shakiba Y, Panjehpour M. Gene expression profiles of CYP24A1 and CYP27B1 in malignant and normal breast tissue. Molecular Medicine Reports 2017; 15: 467-473

21. Zhang X, Harbeck N, Jeschke U, Doisneau-Sixou S. Influence of vitamin D signaling on hormone receptor status and HER2 expression in breast cancer. J Cancer Res Clin Oncol 2017;143:1107-1122. 